\title{
1 Globalisation and development: introduction and overview
}

\author{
Kenneth A. Reinert
}

\section{INTRODUCTION}

Globalisation is a multidimensional concept related to increased interactions of many different kinds among the countries of the world. It is not just the presence of these interactions that matters, however, but also their qualities. This was emphasised by Osterhammel and Petersson (2003) in their history of globalisation when they noted that the use of the label 'globalisation' implies that the interactions have a certain 'regularity' and 'stability' and impact a large number of individuals. Such-labeled globalisation has characterised the world since the beginning of colonisation, taking on new forms beginning in approximately 1870 under the gold standard regime. This first era of modern globalisation lasted through World War I, to be followed by other eras up to the present day. ${ }^{1}$ It is an ongoing reality.

Development is also a multidimensional concept related to growth, structural transformations of many kinds and hoped-for improvement in human well-being. ${ }^{2}$ As noted by Szirmai (2015) in an extended analysis, various forms of human development interact with economic growth processes in rather complex ways that can differ by time and place. The human development aspects of development involve improvements in health and education, declines in fertility rates and increases in agency. ${ }^{3}$ While growth and structural transformation are undeniably central to development processes, it is difficult to provide a single pattern of 'development' that applies always and everywhere. Rather, development proceeds in ways somewhat idiosyncratic to both time and place.

This volume on globalisation and development is part of a larger Elgar handbook series on globalisation. ${ }^{4}$ As such, it engages two multidimensional concepts: globalisation and development. In doing so, it does not impose a particular conception of either. Rather, authors were given full rein to treat these subjects as they thought best in light of their particular inquiries. For this reason, the volume is characterised by conceptual diversity. ${ }^{5}$ The structure of the volume is broadly set in terms of the primary dimensions of globalisation, largely but not exclusively focused on economic dimensions. In this, it reflects the suggestion of Goldin and Reinert (2012) that it is difficult to disentangle the impacts of globalisation on development without getting into the detailed types of globalisation, particularly economic globalisation. The book is therefore structured around seven subjects: international trade, international production, international finance, migration, foreign aid, a broader view and challenges. The section on 'a broader view' delves into dimensions of globalisation that go beyond the mere economic.

A careful reading of the chapters of this volume reveals that globalisation operates through many different channels. For example, the way that the global production networks (GPNs) of multinational supermarkets affect patterns of agricultural trade 


\section{Handbook of globalisation and development}

or the way that illicit trade in wildlife affects the environment is not exactly like the way that equity capital flows affect local equity markets. On the other hand, there are some commonalities: illicit trade in many products has a close relationship to human trafficking and the GPNs of multinational supermarkets are not unrelated in structure to those in other sectors. However, the way that each of these phenomena impact on development processes is not uniform. Without getting into the 'weeds' a bit, we can say very little about globalisation's impacts on development. The analysis of specific processes must replace the recitation of generalisations.

\section{PART I: INTERNATIONAL TRADE}

The volume begins with international trade. Trade in goods is the standard notion of international trade and is one of the oldest forms of globalisation, with roots going back to ancient times. ${ }^{6}$ In Chapter 2, Kenneth A. Reinert introduces the idea of trade in goods, distinguishes it from trade in services and identifies the types of potential gains from trade in goods. He gives a sense of the policy postures to trade in goods that have been in place since the end of World War II and of their development impacts. He takes up the role of trade in goods in the Doha Round of multilateral trade negotiations. He concludes by suggesting that distinctions made between trade in goods and trade in services can lead to the false impression that trade in goods is an independent entity separate from trade in services. This is often not the case because trade in goods (especially manufactured goods) can be dependent on the services sector, including trade in services. ${ }^{7}$

This brings us to Chapter 3 in which Rupa Chanda takes up trade in services in detail and relates increases in services trade to some of the main drivers of globalisation, including advances in information and communication technology (ICT), liberalisation of barriers to services trade and demographic imbalances among countries. She points out that the ongoing increase in the total volume of services trade has begun to involve some key developing countries. Services also account for an increasing share of foreign direct investment (FDI). She emphasises the 'servicification' of non-service sectors and that it is increasingly difficult to disentangle services from other sectors, but also that there is ongoing fragmentation of production processes that can separate out service functions. ${ }^{8}$ Finally, Chanda traces a number of potential routes through which services trade liberalisation can contribute to development, and also highlights how the globalisation of services has thrown up many challenges and dilemmas for governments and international institutions with regard to regulatory reforms in their service sectors, international negotiating strategies and the balancing of commercial interests with public policy objectives in various services.

Agricultural trade is taken up in Chapter 4 by Devesh Roy, with an emphasis on the features of the global 'agri-food system' characterised by extensive GPNs for agricultural commodities that tie into multinational food retail chains. Agricultural production involves land as a key factor of production, and the distribution and use of this asset matters a great deal for agricultural trade outcomes. Consequently, Roy addresses issues of landholdings and the degree to which smallholders can take advantage of the globalisation of agri-food systems in the face of retail developments characterised by increasing concentration in the form of large trading companies and supermarkets. This is part of a 
larger shift in food demand known as the 'nutrition transition' in which traditional food systems are replaced by more industrialised food systems. ${ }^{9}$ There is also an increased role of high-value products in agricultural trade, including fruits, vegetables and products of animal origin (meat, dairy). Roy also gives attention to trade in agricultural inputs such as seeds and chemicals, noting increased market concentration here as well. Here, the issue of intellectual property arises, as discussed further in Chapter 5.

The role of intellectual property in trade and development is taken up in Chapter 5 by Miranda Forsyth. Forsyth considers the intellectual roots of the intellectual property construct up to and including the World Trade Organization's (WTO's) Agreement on Trade Related Aspects of Intellectual Property (TRIPS). She also considers the role of intellectual property provisions in regional or preferential trade agreements (RTAs or PTAs), including what are known as 'TRIPS-Plus' provisions, the role of the World Intellectual Property Organization (WIPO), the relationship of intellectual property rights to the Convention of Biological Diversity (CBD) and, even, links to human rights declarations. Forsyth explicitly considers the relationship between intellectual property and development, including the relative merits of the two policy responses of 'push-back' and 'can't-beat-it-join-it'. She considers a number of relevant 'hot topics' in the intellectual property and development field, including access to medicines, food sovereignty, bio-piracy and cultural misappropriation, and the open-source/open-access movement. ${ }^{10}$ In these ways, she lays out the main issues in a very controversial policy area concerning globalisation and development.

It is important to recognise that international trade is not all sweetness and light, that there is a 'dark side' to globalisation as it relates to trade. This important subject is taken up in Chapters 6 and 7. In Chapter 6, Louise Shelley takes up illicit trade, a subject that sits at the intersection of economics, political economy, national security, criminology and environmental sustainability. Illicit trade covers a wide variety of products: illegal drugs, tobacco products, counterfeit designer brands, counterfeit pharmaceuticals, digital media, art, antiquities, oil, water, timber, wildlife, weapons, child pornography and, even, human beings. Borrowing an evocative phrase from Gastrow (2011), Shelley describes illicit trade as being like 'termites at work', supporting non-state actors and potentially hollowing out and undermining states. It has ties into aspects of financial systems in the realm of money laundering and virtual currencies. Usefully, Shelley links these activities to standard concepts in criminology, namely, 'differential association', 'routine activity theory' and 'dirty togetherness'. Overall, this chapter is a cautionary tale with regard to the intersection of trade and development.

The subject of illicit trade in the form of the drug trade and its impacts on human security is taken up in Chapter 7 by Enrique Desmond Arias. Arias provides the reasons why standard 'national security' notions are less than helpful when understanding the impacts of the drug trade and why a 'human security' framework is more useful. ${ }^{11} \mathrm{He}$ considers the ways in which the drug trade negatively (and sometimes catastrophically) affects human security, usefully casting his analysis in terms of the value chains of different types of illegal drugs that serve the approximately 5 percent of the world population using illegal drugs. He also considers the way that the violence associated with these value chains impacts on political systems, undermining political development (discussed in Chapter 25) and the impacts of drug use on health (discussed in Chapter 29). He takes up a number of development impacts, mostly negative (including corruption) but some positive. 


\section{Handbook of globalisation and development}

As one of the oldest forms of globalisation, international trade has played a key role in development. Tendencies to strip the relationship between trade and development of nuance either in the past (for example, import substitution industrialisation or export promotion) or in the present (for example, food sovereignty) can miss important elements of the relationship. Different kinds of trade, under different policy regimes, can have very different development outcomes. Chapters 2 through to 7 shed some significant light on these nuances.

\section{PART II: INTERNATIONAL PRODUCTION}

The term 'international production' refers to the activities of firms that span national boundaries. It can include trading relationships, contracting and foreign direct investment (FDI), all arrayed throughout evolving GPNs and evolving strategies of foreign market entry. ${ }^{12}$ This realm of globalisation is historically more recent than international trade and came to the fore during the gold standard era mentioned above. In Chapter 8 , John C. Anyanwu takes up the last of these, foreign direct investment, stating that FDI 'is crucial to the attainment of sustained growth and development, especially in the developing nations of the world'. Foreign direct investment itself can take place through a number of different processes, and these are usefully detailed in the chapter. Anyanwu reviews the theoretical approaches to understanding FDI and reviews the stylised facts with regard to global FDI flows. He then turns to the motives for and drivers of global FDI flows, drawing on the classic work of Dunning (1977) and Dunning and Lundan (2008) and providing a thorough review of the research literature. He then considers the issues of FDI incentives and policies to best leverage this feature of globalisation for development.

Pralok Gupta takes up the broader issue of global production networks in Chapter 9. This chapter relates directly to Chapter 8 on FDI, but also to Chapter 2 on trade in goods and, more closely, to Chapter 3 on trade in services. He considers the conceptual history of GPNs from the notion of commodity chains (for example, Gereffi 1996), to the subsequent notion of global value chains (for example, Gereffi et al. 2005) and, finally, that of GPNs (for example, Henderson et al. 2002). Gupta considers the history and evolution of GPNs, including the reasons for their emergence and the role of GPNs in globalisation and development. Importantly, he considers the distribution of value added along GPNs, noting that the actual manufacturing stage often accounts for a small fraction of the total value added. This brings him to consider the role of services within GPNs and the notion, discussed in Chapter 3, of 'servicification'. ${ }^{13}$ Finally, Gupta reviews emerging research on GPNs, including the Organisation for Economic Co-operation and Development's (OECD's) Trade in Value Added (TiVA) database and relevant WTO data. As this chapter makes clear, the ongoing development of GPNs is a critical aspect of the global economy, and the roles of countries in these GPNs have important implications for ways that global production impacts development.

In Chapter 10, Sarianna M. Lundan takes up the governance of multinational enterprises (MNEs). She considers this issue from two perspectives: from the viewpoint of the owners and managers of the firm (for example, self-governance) and the viewpoint between the subsidiaries and local actors in the host countries. She pays attention to the 
growing role of MNEs from developing or emerging economies. One issue addressed is the ownership structures of MNEs, and another is the extent to which hard-and-fast borders of these firms have evolved into looser networks of activities characterised by non-equity modalities (NEMs). ${ }^{14}$ Finally, Lundan takes up the expanded role of MNEs within larger societies, including corporate social responsibility, public-private partnerships, collaborative relationships outside of traditional enclaves and their place within emerging systems of supra-national regulation and agreements. Some of these latter issues are taken up in Chapter 26 on global organisations.

In the final chapter in the realm of international production, Chapter 11, Kimberly Ann Elliott takes up the issue of labor standards. Always important, this issue took on a new urgency in the wake of the Rana Plaza clothing factory collapse in Bangladesh in which more than 1000 workers perished. As has been pointed out by Bowden (2014) and Elliott, labor-intensive export sectors are both the most likely to contribute to poverty alleviation and be characterised by incentives to try to economise on labor costs by compromising on safety. Elliott also addresses the perennial issue of whether globalisation imposes a 'race to the bottom' in labor standards. While there is some ambiguity in the empirical evidence on this issue, her overall conclusion is that such a race to the bottom is not necessarily the norm. Further, the pursuit of labor standards, including the International Labour Organisation's (ILO) core labor standards, can mitigate against this possibility. In addition to these, there are other ongoing efforts in the realm of private sector codes and monitoring, labor standards in trade agreements and the Better Work program, a joint project of the ILO and the International Finance Corporation (IFC).

Patterns of international production have changed significantly over the past few decades. Understanding these changes, and their implications for development, is therefore an ongoing process. The orthodox economic default position that private activity in the realm of international production is always welfare enhancing is not sufficient to understand the subtleties involved in the production-development nexus. Chapters 8 through to 11 help to draw out some of these subtleties.

\section{PART III: INTERNATIONAL FINANCE}

Part III of this volume takes up the complicated realm of international finance. While it is tempting to treat the financial aspects of globalisation in one lump, it is clear from the treatment of this issue by Goldin and Reinert (2012), among others, that different types of global financial transactions can have very different development outcomes. Consequently, this part takes a more nuanced approach. It begins in Chapter 12 with an analysis of equity markets by Odongo Kodongo and Kalu Ojah. These authors begin with a review of the role of finance in development and then turn to the specific case of equity markets and development. They note that the world economy is now characterised by an increased level of interaction between emerging-market equity markets and more standard equity markets and that this can increase market volatility. However, this increased market integration has only progressed so far, and evidence of continued segmentation appears in a number of guises, most importantly in persistent risk premia. In concert with a number of other observers, Kodongo and Ojah suggest that developing countries should carefully sequence the implementation of financial liberalisation with prudential 
institutional and legal reforms. ${ }^{15}$ They use an international asset pricing model (IAPM) to help sort through the empirical evidence on these issues.

Lena Rethel and Iain Hardie next take up bond markets in Chapter 13. They emphasise the ability of bonds to be broken up into relatively small denominations, contributing to the liquidity of both primary and secondary bond markets, the practice of securitisation and the role of bonds in financing government debt. They note that the study of bond markets has become an interdisciplinary field rather than just the purview of economists and financial experts. Rethel and Hardie take an historical approach to the role of bond finance in development and consider alternative measures of bond market development. Finally, they consider a few emerging areas of research, including efforts to establish a regional bond market in East Asia and the role of Islamic bonds in emerging markets.

Chapter 14 turns to global banking and development. In this realm, Sasidaran Gopalan usefully distinguishes among three processes, namely, banking globalisation, capital account liberalisation and domestic deregulation. He notes that these three processes can interact with one another in a number of different ways with various implications depending on the context. Further, banking globalisation is achieved both through FDI and foreign bank entry, as well as through cross-border banking activities (lending and borrowing). ${ }^{16}$ He provides useful visual representations of these various aspects of banking globalisation and liberalisation. Turning to the research literature, Gopalan thoroughly reviews the role of both foreign banks international financial openness in financial development, including financial deepening, and the role of foreign banks in financial inclusion, including the possibility of foreign banks 'cherry picking' the most creditworthy borrowers. He notes the institutional and governance prerequisites for these processes to support financial development, including adequate prudential supervision, accounting and disclosure standards, legal protection for creditors and transparency. Recognition of the institutional and governance prerequisites for the positive involvement of banking in development leads to a consideration of threshold effects in more recent empirical studies of the issue (for example, Gopalan 2015).

With the key issues surrounding equity markets, bond finance and bank lending established, James K. Boyce and Léonce Ndikumana take up the issue of external debt and capital flight in Chapter 15. These authors examine the extent and magnitude of external debt and the role of the Highly Indebted Poor Country (HIPC) initiative and the Multilateral Debt Relief Initiative (MDRI) in reducing debt levels. They then consider the issue of capital flight, including the difficulties that arise in measuring it. They relate the capital flight process to the distinct but related phenomenon of illicit financial flows. Boyce and Ndikumana consider external debt and capital flight to be 'dual phenomena' characterised by specific interrelationships and hysteresis effects that they identify and discuss. Curtailing capital flight requires an institutional restructuring of 'perverse' incentive structures. This includes stolen asset recovery, selective debt repudiation and regulatory reforms in international banking. Boyce and Ndikumana make clear that debt and capital flight have a number of significant development impacts.

The final chapter of the international finance part of this volume, Chapter 16 by Gerald Epstein, takes up the policy of capital controls or capital account regulations (CARs). Up until 2010, the official view of many orthodox economists and of the International Monetary Fund (IMF) was that CARs were undesirable and inappropriate. Indeed, full capital account convertibility was considered as an official policy of the IMF in 1997 on 
the eve of the Asian financial crisis. However, as Epstein describes, these views have been modified, most notably by Ostry et al. (2010). Epstein sets these changes into a larger historical context all the way through the 2007-08 crisis to the present. He sets out the numerous potential objectives of CARs on both capital inflows and outflows and then reviews the growing empirical evidence on their effectiveness, including the ways in which both CARs are measured and the choice of effectiveness variables. ${ }^{17}$ The chapter gives a sense of the research literature to date and its limitations. Epstein concludes that CARS are often effective at limiting inflows and some outflows, at least temporarily, and can help to achieve some level of monetary policy and exchange rate autonomy. However, additional research is needed to determine more precisely which types of CARS are most effective in specific contexts.

Finance is one of the stickiest aspects of globalisation and development. The types of financial instruments involved are sufficiently varied to make broad impact assessments all but impossible, and the empirical evidence on any specific type of finance often proves to be inconclusive. What we do know is that global financial transactions are much more important than trade transactions and have proven on numerous occasions to be both volatile and potentially destructive. ${ }^{18}$ It is these characteristics of finance that suggest that policymakers need to be cautious in assessing the role of global finance in development. Finance can help, but needs the right conditions to do so. Chapters 12 through to 16 give us a sense of the need for this caution and the conditions under which global finance can help.

\section{PART IV: MIGRATION}

As emphasised by Goldin et al. (2012), migration is one of the oldest forms of globalisation. This part offers a number of perspectives on this important socio-economic process. It begins in Chapter 17 where Irena Omelaniuk treats migration as a 'defining feature of globalisation', or a third pillar alongside international trade and international finance, but without a comparable system of global governance. She considers both international and internal migration, totaling more than 1 billion individuals, and their contributions to diversity, urbanisation and development. She contrasts legal and irregular migration and takes up the issue of forced and crisis migration. Omelaniuk explores the links between global labor mobility and development, including the role of diasporas. Migration raises a number of questions about globalisation, such as how to protect globally mobile workers, make skills and qualifications more portable and manage mass displacements. Finally, she considers legal and institutional frameworks for governing migration, both multilateral and regional. While the private sector is seen as key to future migration governance, she is skeptical about the feasibility and need for a global migration regime.

In Chapter 18, Philip Martin and Ibrahim Sirkeci take up where Irena Omelaniuk left off to consider the 'three Rs' of migration and development, namely, recruitment, remittances and returns. As Martin and Sirkeci describe, these three processes can result in either virtuous or vicious migration and development circles. These researchers emphasise that 'no law ensures that more labor migration promotes virtuous development circles'. The actual result depends on both the circumstances surrounding the migration flow and the policy regime. At over US $\$ 400$ billion a year, remittances have been a particular focus 
of researchers and policymakers and can contribute directly to poverty alleviation. Martin and Sirkeci also consider the relationship between migration and trade, in particular the trade-as-a-substitute-for-migration hypothesis, which they hold up to critical evaluation using the relevant example of the North American Free Trade Agreement (NAFTA).

If illicit trade composes the dark side of trade and development, then human trafficking or trafficking in human beings (THB) holds the same place for migration and development. In Chapter 19, Amanda Klekowski von Koppenfels takes up this issue from a broad, social science perspective. Von Koppenfels stresses that THB is widely acknowledged as a grave human rights abuse and significant challenge for the international community'. She outlines the 'push' and 'pull' factors behind THB and considers the distinction between trafficking and smuggling, as well as grey areas between the two. Von Koppenfels directly addresses the issue of the quantification of THB activity, largely concluding that we are not able to get a quantitative handle on the phenomenon despite many suggestions to the contrary. She then turns to counter-trafficking efforts, including the three 'Ps' (prevention, protection and prosecution) and the three 'Rs' (rescue, removal and reintegration). In doing so, she makes an important distinction between protecting borders and protecting human rights, noting that the former can compromise the latter. Together with Chapters 6 and 7, this chapter is a real cautionary tale about simplistically equating globalisation and development. ${ }^{19}$

Chapter 20 takes up the issues of brain drain, gain and circulation. In it, Zovanga L. Kone and Çağlar Özden focus on high-skilled migration. They begin the chapter with a thorough review of high-skilled migration patterns, noting that the data are far from perfect and concisely describing their limitations. As part of this discussion, they compare various definitions of high-skilled migration and the importance of place of birth versus place of education distinction. They then consider the issue of brain drain, a subject that goes back to the work of Grubel and Scott (1966) and Bhagwati (1976). They consider potential source-country losses of human capital, incomes and tax revenues. Next, they consider the potential outcome of brain gain where high-skilled emigration puts upward pressure on wages and generates a supply effect that might outweigh the initial human capital loss. This leads to the subject of brain circulation within networks, an idea first formalised by Saxenian (2005). Kone and Ozden consider a number of different channels through which brain circulation can take place and the policy questions involved. In these ways, the chapter forms a valuable complement to Chapters 17 and 18 .

While migration is one of the oldest forms of globalisation, it continues to be both controversial in national and regional political processes. It is also not as well understood as other globalisation processes, having received less attention by researchers and policy analysts. Chapters 17 through to 20 give us a better sense of this aspect of globalisation in its many sub-processes and effects. International migration and international migration policy is an area most deserving of increased policy analysis and institution building.

\section{PART V: FOREIGN AID}

As a result of the activities of multilateral and regional development banks, as well as that of selected national governments, foreign aid is an important part of the globalisation process. Unlike trade, FDI and migration, however, foreign aid is a relatively recent 
phenomenon with roots in the post-colonial era. ${ }^{20}$ Nevertheless, foreign aid has had significant effects, both in terms of resource redistribution and as a channel for development ideas and development policies. ${ }^{21}$ However, it has been plagued by allegations of ineffectiveness that continue to this day and form an active research area. ${ }^{22}$

Much of the literature on foreign aid concerns its degree of effectiveness. This area of research is controversial and is considered in depth by Mina Baliamoune-Lutz in Chapter 21. Baliamoune-Lutz focuses on the evidence concerning the effects of development assistance on economic growth and other measures of 'development'. Non-growth aspects of development considered include human capital (health and education), the promotion of FDI and the empowerment of women. For each of these, Baliamoune-Lutz carefully reviews the empirical literature to date, noting issues of data, variable choice and conflicting results. A number of explanatory factors are considered, including 'good' policy, institutions and social cohesion. She then turns to the issue of aid dependency and its effects on policy formation, institutional reforms and capacity building, as well as the issue of potential 'Dutch disease' effects. Despite the ongoing controversies, it is now clear that institutions and social cohesion are at least as relevant as 'good policy' and that we need more focused evaluations of the role of foreign aid in globalisation and development processes.

In Chapter 22, Jennifer Clapp takes up the issue of food aid, noting that this type of aid has been characterised by significant changes in recent decades. This included a shift from a surplus food approach, strongly influenced by Cold War considerations, to greater considerations of poverty and emergencies after the 1974 World Food Conference. Clapp describes the evolving political economy of food aid, including the roles of policy and politics, and the analysis of these from various social science disciplines. She then turns to more recent changes, including a move from tied to untied food aid. This reduces the connection of aid flows to supply-side cycles and allows for sourcing food aid closer to where it is needed. In these ways, it is a move away from the 'dumping' aspect that has characterised food aid and that violates the spirit if not the letter of multilateral trade agreements. ${ }^{23}$ Clapp also considers the food price volatility of 2007-08 and 2010-13, their causes and their poverty impacts. Finally, she considers the 2012 Food Assistance Convention that replaced the 1967-99 Food Aid Convention and its shift from aid denominated in minimum amounts of physical units to aid denominated in donor currency terms. Clapp considers both the advantages and disadvantages of this new regime.

Foreign aid is not always considered to be an aspect of globalisation, but a number of considerations suggest that it is. It involves international transfers of various kinds and has knock-on effects in the realms of trade, international production and finance. Perhaps inevitably, foreign aid will always be a controversial aspect of the globalisation and development process. Chapters 21 and 22 make some of the issues in this controversy more clear so that we can better understand the ongoing research on foreign aid and development.

\section{PART VI: A BROADER VIEW}

We began this introductory chapter stating that globalisation is a multidimensional concept. Some of these dimensions lie outside the standard realm of economic 
globalisation, and it is important to have an appreciation of these. This part considers a few of these dimensions in order to develop a broader view, including culture, technology, politics and organisations. Each of these is an aspect of globalisation, and each has development impacts. The development impacts of these realms can be under-emphasised (for example, culture) or over-emphasised (for example, technology). Nevertheless, we cannot come to a full understanding of the globalisation-development nexus without them.

Paul James takes up the issue of culture in Chapter 23. In doing so, he explicitly links the concept of culture to the two main concepts of this volume: globalisation and development. Indeed, his chapter is structured around the definitions of these three terms: globalisation, culture and development. James describes the ways in which the notion of culture is pushed aside in most standard considerations of globalisation and development as either an ancillary supporting factor or, even, as an unfortunate restraining factor. ${ }^{24} \mathrm{He}$ also emphasises a fourth concept (also emphasised in this volume), namely, 'the economy'. This concept, too, tends to force culture into the background. James emphasises that processes of globalisation, culture and development are related in many ways but that notions of 'the economy' and 'modernity' (evidenced in the distinction made between 'developed' and 'developing' countries) should not necessarily take precedence over culture but be considered on an equal basis with it. ${ }^{25} \mathrm{He}$ also considers issues of the natural environment and sustainability. The chapter is a very useful reminder that we deploy our terms and concepts with consequences, and that we do not always deploy them carefully.

In Chapter 24, J.P. Singh takes up the issue of technology (see also, Archibugi and Michie 1995). He recognises the interconnections of technology to the other realms of globalisation when he states that 'technological use and adaptation are part of the social and political context in a country'. He begins this consideration with the standard (exogenous) growth theory of Solow (1957) and improvements on this in the forms of endogenous and evolutionary growth theory and the new institutional economics of North (1994). Singh sets out a number of active research areas relevant to the role of technology in globalisation, including agricultural technologies, product cycles and technology transfer, and industrial districts and innovation policies. He then takes up the issue of technology and the 'global information economy'. The latter is an important driver of modern globalisation in services trade, GPNs and logistics coordination, and financial market integration. In all of these aspects, technology has development impacts that need to be better understood.

Among development policy practitioners, the issue of political development is often ignored. The assumption is that, once a policy is devised, it should simply be put into practice, with too little attention paid to the political systems that must be engaged to do so. In Chapter 25, Damien Kingsbury addresses directly the issue of political development, noting that in the development field the subject is 'all but unheard of' ${ }^{26}$ Kingsbury sets out the issue of political development within the notion of political freedoms emphasised by Sen (1999) and the relative roles of economic and political development within larger development processes. Kingsbury addresses the origins of political development in the concepts of equality, political system capacity, and specialisation of state institutions and the process of decolonisation. He considers the role of political identity and its links to colonial histories, as well as the problematic role of the military. He then takes on the issues of democracy, democratisation and regime change. The last of these again raises the issue of the relative roles of economic and political development. Finally, Kingsbury takes 
up the issue of state institutions and governance. His chapter is an important reminder that political development is an often ignored but critical aspect of development and that it takes place within a global political environment.

Economists in particular, but also social scientists in general, tend to ignore the role of organisations in socio-economic processes, including development processes. In Chapter 26, Gelaye Debebe takes on this issue by examining a set of global organisations with development impacts. These organisations are: international governmental organisations (IGOs), international non-governmental organisations (INGOs) and MNEs. Debebe reviews the basic characteristics of these three organisational types and considers their role in development from a historical perspective. The chapter also considers how these three types of organisations have interacted over time within the broad United Nations system. It pays particular attention to multilateral efforts to govern MNEs in order to achieve better development outcomes. In this way, she builds on Chapter 10 of this volume. What becomes clear from this chapter is that, for decades, MNEs have escaped from any of the binding, de minimus guidelines called for by Goldin and Reinert (2012), among others. ${ }^{27}$

Chapters 23 to 26 help us cast the globalisation and development subject area into a broader context. They remind us that the narrow focus on the economic dimensions of globalisation and development, while useful, also has limitations. There is much to be learned from opening our view up to a broader set of perspectives.

\section{PART VII: CHALLENGES}

To say the least, the global policy community faces a daunting list of contemporary development challenges. Without trying to be exhaustive, this part considers a few of these, including poverty and inequality, economic rights, and global health. Each of these reflects important aspects of globalisation and development processes, and the word 'challenge' is used purposefully. These issues and the policy questions they bring up are indeed challenging, perhaps more so than the global institutional capacities to address them. Indeed, there is no evidence of these challenges becoming less pressing in the foreseeable future.

The first challenge is that of poverty and inequality, and this is taken up in Chapter 27 by David A. Clark, Shailaja Fennell and David Hulme. These authors rightly note that both poverty and inequality are not easily defined concepts. They approach the definitional question through three broad 'meta-dimensions', namely, depth (or severity), breadth (or the variety of deprivations involved) and duration (time spent disadvantaged). They take up each of the meta-dimensions of poverty and inequality in three separate sections of their chapter. In the realm of depth, they take the standard neoclassical approach as their starting point and consider measures associated with income thresholds, headcounts and gaps. With regard to breadth, they consider alternative conceptions of the improvement of human well-being, particularly those such as the capability approach and human development movement that offer alternatives to the standard growth paradigm. ${ }^{28}$ Clark et al. then consider the important issue of duration and the associated phenomenon of chronic poverty. Next, they consider 'fuzzy' and 'vague' approaches to poverty and inequality that recognise and allow for a degree of imprecision in defining and 
measuring these concepts. They also consider the complex relationship between poverty and inequality. Finally, they explore the spatial dimensions of poverty and inequality by presenting data on their incidence across regions of the world. The chapter serves as a concise and up-to-date survey of a number of key conceptual and measurement issues surrounding this important global challenge.

In Chapter 28, Christopher Jeffords takes up the issue of economic rights. ${ }^{29}$ Jeffords begins with the origins of economic and social rights found within the Universal Declaration of Human Rights and the International Covenant on Economic, Social, and Cultural Rights. These declarations and subsequent clarifications via 'General Comments' provide a framework of rights to food, water, sanitation, health, education, housing, work and social security. In some cases, these principles have found their way into national constitutions, particularly in the case of younger countries. The chapter focuses on quantitative research on economic and social rights. Jeffords considers the 'residual approach' and the Social and Economic Rights Fulfillment (SERF) Index as means of economic and social rights fulfillment in general. He then assesses quantitative research of specific economic and social rights. These include social security and guaranteed jobs, constitutional environmental rights, women's economic rights, education, poverty and health. The chapter serves as a window into a particular view of globalisation and development through a rights-based framework.

The issue of health is taken up in Chapter 29. Ted Schrecker critically evaluates the claim that 'globalisation is good for your health'. He does so with a focus on several key areas. In trade policy, issues include how the diffusion of medical technologies is impeded by intellectual property protection under the WTO regime (see Chapter 5) and trade agreements with 'TRIPS-plus' provisions, ${ }^{30}$ investor-state dispute settlement (ISDS) provisions, and FDI's role in the above mentioned nutrition transition. Schrecker also considers crossborder markets for health-care services and agricultural land, medical brain drain, and the direct and indirect health impacts of international finance, addressing macroeconomic conditionalities and financial crises. Finally, and perhaps most fundamentally, he relates the subject of Chapter 27 of this volume (poverty and inequality) to health outcomes, while suggesting that national governments often have more scope for addressing these conditions and their health consequences should they wish to do so. In these ways, Chapter 29 illustrates the many pathways in which globalisation processes can impact health outcomes.

\section{CONCLUDING NOTE}

Despite this volume's 29 chapters, the subject matter of the work is very broad. It is hoped that the reader will find the work useful as an entry point into, and research source for, the subjects and issues they wish to pursue further. Much of the volume covers contested terrain, but the issues of debate should become clear through the chapters' treatment of each subject area. There will always be a sense, in the words of Hoff and Stiglitz (2001, p. 428) that 'we know that we do not know', but this is probably both inescapable and ultimately productive. The issues surrounding globalisation and development will be researched and debated for decades to come. 


\section{NOTES}

1. See Chapter 1 of Goldin and Reinert (2012).

2. Davis $(2009$, p. 277) wrote that 'Economic development is generally facilitated by a number of structural changes, including urbanisation, the rise in the size of firms, the relative decline of the agricultural sector in terms of employment and output with expansion of manufacturing and services, the geographic expansion of markets, and increases in the diversity of goods produced and traded'.

3. Agency is no doubt an over-used term, but the World Bank $(2011$, p. 6) has provided a useful definition: 'Agency is about one's ability to make choices - and to transform them into desired actions and outcomes. Across all countries and cultures, there are differences between men's and women's ability to make these choices, usually to women's disadvantage'. This quote alludes to gender issues in development, and these compose a further important realm of transformation.

4. For the genesis of the series, see Michie (2011).

5. The concepts of globalisation and development are critically evaluated in Chapter 23 of this volume, on culture.

6. For one analysis of ancient patterns of trade in goods, see Adams et al. (1974).

7. See Arnold et al. (2011) for the case of Czech Republic and Arnold et al. (forthcoming) for the case of India. More generally, see Nordås and Rouzet (2015).

8. This was first pointed out by Bhagwati (1984).

9. On the nutrition transition, see Popkin (1993).

10. For an earlier treatment of some of these broader issues, see each of the chapters in Bellmann et al. (2003). Access to medicines is also considered in Chapter 29 of this volume on global health. See also Abbott and Reichman (2007).

11. For an early contribution, see Kaldor et al. (2007).

12. See, for example, Chapters 1, 9 and 10 of Reinert (2012).

13. In addition to the discussion in Chapters 3 and 9 on servicification, see Lodefalk (2013).

14. See UNCTAD (2011).

15. See, for example, Rodrik and Subramanian (2009).

16. Foreign direct investment or foreign band entry is Mode 3 of the General Agreement on Trade in Services (GATS), commercial presence.

17. Effectiveness variables include capital flow volumes, capital flow compositions, monetary policy autonomy, the real exchange rate, inflation, and asset price volatility.

18. See, for example, Chapter 4 of Goldin and Reinert (2012).

19. See also Shelley (2010).

20. As noted by Goldin and Reinert (2012, p. 113), for example, 'although ideas, goods, investments, and people have crossed great distances for millennia in response to a host of economic opportunities, it is only relatively recently that governments began to provide financial and technical assistance to foreign countries'.

21. See, for example, Chapter 5 of Goldin and Reinert (2012).

22. See, for example, Chapter 14 of Szirmai (2015), and Berlin (2015).

23. Another important change noted by Clapp is the emergence of new food aid donors, including Brazil, China and Russia.

24. See also Chapter 12 of Szirmai (2015).

25. A similar point was made by Slim (1995).

26. An exception to this general rule is Szirmai (2015) who devotes a full chapter to the subject.

27. This is true even of the most recent version of the OECD Guidelines for Multinational Enterprises (OECD 2011). See, for example, Reinert et al. (2016).

28. See, for example, Sen (1989), Nussbaum (2000, 2011) and Clark (2006).

29. For an earlier review, see also Hertel and Minkler (2007). For an important contribution to the notion of rights themselves, see Shue (1996).

30. On this issue, see also Abbott and Reichman (2007).

\section{REFERENCES}

Abbott, F. and J.H. Reichman (2007), 'The Doha Round's public health legacy: strategies for the production and diffusion of patented medicines under the amended TRIPS provisions', Journal of International Economic Law, 10 (4), 921-87. 
Adams, R. McC. (1974), 'Anthropological perspectives on ancient trade', Current Anthropology, 15 (3), $239-58$. Archibugi, D. and J. Michie (1995), 'The globalisation of technology: a new taxonomy', Cambridge Journal of Economics, 19 (1), 121-40.

Arnold, J.M., B.S. Javorcik and A. Mattoo (2011), 'Does services liberalization benefit manufacturing firms: evidence from the Czech Republic', Journal of International Economics, 85 (1), 136-46.

Arnold, J.M., B.S. Javorcik, M. Lipscomb and A. Mattoo (forthcoming), 'Services reform and manufacturing performance: evidence from India', Economic Journal.

Bellmann, C., G. Dutfield and R. Meléndiz-Ortiz (eds) (2003), Trading in Knowledge: Development Perspectives on TRIPS, Trade and Sustainability, London: Earthscan.

Berlin, M.P. (2015), 'The aid effectiveness literature: is it over yet?', FREE Policy Briefs, Forum for Research on Eastern Europe and Emerging Economies, 16 February, accessed 24 October 2016 at http://freepolicybriefs. org/2015/02/16/the-aid-effectiveness-literature-is-it-over-yet/.

Bhagwati, J. (1976), The Brain Drain and Taxation: Theory and Empirical Analysis, Amsterdam: North Holland.

Bhagwati, J.N. (1984), 'Splintering and disembodiment of services and developing nations', World Economy, 7 (2), 133-43.

Bowden, B. (2014), 'Bangladesh clothing factory fires: the way forward', South Asian Journal of Human Resources Management, 1 (2), 283-8.

Clark, D.A. (2006), 'Capability approach', in D.A. Clark (ed.), The Elgar Companion to Development Studies, Cheltenham, UK and Northampton, MA, USA: Edward Elgar, pp. 32-45.

Davis, L. (2009), 'Development', in K.A. Reinert, R.S. Rajan, A.J. Glass and L.S. Davis (eds), The Princeton Encyclopedia of the World Economy, Princeton, NJ: Princeton University Press, pp. 277-80.

Dunning, J.H. (1977), 'Trade, location of economic activity and the MNE: a search for an eclectic approach', in B. Ohlin and P.O. Hesselborn (eds), The International Allocation of Economic Activity, London: Macmillan, pp. 395-418.

Dunning, J.H. and S.M. Lundan (2008), Multinational Enterprises and the Global Economy, Cheltenham, UK and Northampton, MA, USA: Edward Elgar.

Gastrow, P. (2011), Termites at Work: Transnational Crime and State Erosion in Kenya, New York: International Peace Institute.

Gereffi, G. (1996), 'Global commodity chains: new forms of coordination and control among nations and firms in international industries', Competition and Change, 1 (4), 427-39.

Gereffi, G., J. Humphrey and T. Sturgeon (2005), 'The governance of global value chains', Review of International Political Economy, 12 (1), 78-104.

Goldin, I. and K.A. Reinert (2012), Globalization for Development: Meeting New Challenges, Oxford: Oxford University Press.

Goldin, I., G. Cameron and M. Balarajan (2012), Exceptional People: How Migration Shaped Our World and Will Define Our Future, Princeton, NJ: Princeton University Press.

Gopalan, S. (2015), 'Does foreign bank entry contribute to financial depth? Examining the role of income thresholds', mimeo, Hong Kong University of Science and Technology.

Grubel, H.B. and A.D. Scott (1966), 'The international flow of human capital', American Economic Review $56(1-2), 268-74$

Henderson, J., P. Dicken, M. Hess, N. Coe and H.W.-C. Yeung (2002), 'Global production networks and the analysis of economic development', Review of International Political Economy, 9 (3), 436-64.

Hertel, S. and L. Minkler (2007), 'Economic rights: the terrain', in S. Hertel and L. Minkler (eds), Economic Rights: Conceptual, Measurement, and Policy Issues, New York: Cambridge University Press, pp. $1-35$.

Hoff, K. and J.E. Stiglitz (2001), 'Modern economic theory and development', in G.M. Meier and J.E. Stiglitz (eds), Frontiers of Development Economics: The Future in Perspective, Oxford: Oxford University Press, pp. 389-459.

Kaldor, M., M. Martin and S. Selchow (2007), 'Human security: a new strategic narrative for Europe', International Affairs, 83 (2), 273-88.

Lodefalk, M. (2013), 'Servicification of manufacturing - evidence from Sweden', International Journal of Economics and Business Research, 6 (1), 87-113.

Michie, J. (2011), 'Globalisation: introduction and overview', in J. Michie (ed.), The Handbook of Globalisation, Cheltenham, UK and Northampton, MA, USA: Edward Elgar, pp. 1-16.

Nordås, H.K. and D. Rouzet (2015), 'The impact of services trade restrictiveness on trade flows: first estimates', OECD Trade Policy Papers No. 178, Organisation for Economic Co-operation and Development, Paris.

North, D.C. (1994), 'Economic performance through time', American Economic Review, 84 (3), $359-68$.

Nussbaum, M.C. (2000), Women and Development: A Capabilities Approach, Cambridge: Cambridge University Press.

Nussbaum, M.C. (2011), Creating Capabilities: The Human Development Approach, Cambridge, MA: Harvard University Press. 
Organisation for Economic Co-operation and Development (OECD) (2011), OECD Guidelines for Multinational Enterprises: 2011 Edition, Paris: OECD.

Osterhammel, J. and N.P. Petersson (2003), Globalization: A Short History, Princeton, NJ: Princeton University Press.

Ostry, J.D., A.R. Ghosh, K. Habermeier, M. Chamon, M.S. Qureshi and D.B.S. Reinhardt (2010), 'Capital inflows: the role of controls,' IMF Staff Position Note SPN/10/04, International Monetary Fund.

Popkin, B.M. (1993), 'Nutritional patterns and transitions', Population and Development Review, 19 (1), $138-57$.

Reinert, K.A. (2012), An Introduction to International Economics: New Perspectives on the World Economy, Cambridge: Cambridge University Press.

Reinert, K.A., O.T. Reinert and G. Debebe (2016), 'The new OECD Guidelines on Multinational Enterprises: better but not good enough', Development in Practice, 26 (6), 816-23.

Rodrik, D and A. Subramanian (2009), 'Why did financial globalization disappoint?', IMF Staff Papers, 56 (1), 112-38.

Saxenian, A. (2005), 'From brain drain to brain circulation: transnational communities and regional upgrading in India and China', Studies in Comparative International Development, 40 (2), 35-61.

Sen, A. (1989), 'Development as capability expansion', Journal of Development Planning, 19, 41-58.

Sen, A. (1999), Development as Freedom, New York: Knopf.

Shelley, L. (2010), Trafficking: A Global Perspective, New York: Cambridge University Press.

Shue, H. (1996), Basic Rights: Subsistence, Affluence, and U.S. Foreign Policy, Princeton, NJ: Princeton University Press.

Slim, H. (1995), 'What is development?', Development in Practice, 5 (2), 143-8.

Solow, R.M. (1957), 'Technical change and the aggregate production function', Review of Economics and Statistics, 39 (3), 312-20.

Szirmai, A. (2015), Socio-Economic Development, Cambridge: Cambridge University Press.

United Nations Conference on Trade and Development (UNCTAD) (2011), World Investment Report 2011. Non-Equity Modes of International Production and Development, Geneva: UNCTAD.

World Bank (2011), World Development Report 2012: Gender Equality and Development, Washington, DC: World Bank. 
Kenneth A. Reinert - 9781783478651 